\title{
Early diagnosis of HIV-I infection in infants using RNA Quantitative PCR in Burkina Faso
}

\author{
Hermann Somlare*1,2, Lassana Sangare ${ }^{1,3}$, Saydou Yamegogo 1,2, \\ Carine Ouedraogo ${ }^{2}$, Yolande Dembel ${ }^{1}$, Monique Soro ${ }^{2}$, Parfait Some ${ }^{4}$ and \\ Caroline Yonaba ${ }^{4}$
}

Address: ${ }^{1}$ Laboratory of Bacteriology and Virology of Hospital University Center Yalgado Ouédraogo, West Africa, Burkina Faso, ${ }^{2}$ UFR Sciences de la Vie et de la Terre of Unviersity of Ouagadougou, West Africa, Burkina Faso, ${ }^{3}$ UFR Sciences de la Santé, West Africa, Burkina Faso and ${ }^{4}$ Paediatric clinic of Hospital University Center Yalgado Ouédraogo, West Africa, Burkina Faso

* Corresponding author

from Fifth Dominique Dormont International Conference. Mother-to-child transmitted viral diseases: from transmission to children care Paris, France. 26-28 March 2009

Published: 22 July 2009

Retrovirology 2009, 6(Suppl I):PI0 doi:10.1 186/I742-4690-6-SI-PI0

This abstract is available from: http://www.retrovirology.com/content/6/SI/PIO

(c) 2009 Somlare et al; licensee BioMed Central Ltd.

\section{Aim of study}

To diagnose HIV infection in African infants born to HIV1 infected mothers using Abbott RealTime PCR (Abbott Molecular).

\section{Materials and methods}

From January to December 2008, 114 infants born to HIV-1 infected mothers were referred to the University Hospital Yalgado Ouédraogo (Ouagadougou, Burkina Faso), for early diagnosis of HIV infection. Two to $3 \mathrm{~mL}$ of blood sample were collected on EDTA/K3 microtubes from each infant. After centrifugation, the plasma samples were stored at $-80^{\circ} \mathrm{C}$, until their use. HIV-1 RNA was detected in each sample using Abbott RealTime HIV-1 Assay (Abbott Molecular) and m2000rt protocol: the RNA detection threshold was 40 copies $/ \mathrm{mL}$ (1.6 Log). From each infant with RNA positive result, a second plasma sample was collected 4 weeks later to confirm the previous RNA result Sociodemographic data were collected from the infants and analysed.

\section{Results}

The mean age of the newborns was 4,5 months, and the sex ratio was 0.92 . The HIV RNA PCR assay was positive in 14/144 (9.7\%) newborns in both samples tested: the mean viral load was 4,135,853 copies/mL (6.6 Log copies $/ \mathrm{mL}$ ), and the mean CD4 percentage was $20.25 \%$.
Nineteen children and their mothers did not receive dual antiretroviral prophylaxis (AZT+NVP) for the prevention of mother to child transmission (PMTCT): 13 (68.4\%) of them were HIV-positive against only $1(0.8 \%)$ among the 125 who received the prophylaxis. The HIV-1 transmission rate was significantly higher in children without PMTCT $(p=0.00)$. Ten $(71.4 \%)$ HIV-positive infants were breast-fed exclusively, 2 (14.3\%) received mixed breastfeeding and 2 (14.3\%) received formula: exclusively breast-feeding could be a higher risk of HIV transmission than the 2 other routes.

\section{Conclusion}

These results showed that Abbott RealTime HIV-1 assay for the quantitation of HIV-1 can be used for the early diagnosis in HIV-exposed infants, even in newborns who received antiretroviral prophylaxis. The exclusive breastfeeding appears as high risk of HIV transmission from infected mothers to their children. 